\title{
Correction to: Prognostic Significance of Preoperative Osteopenia in Patients Undergoing Esophagectomy for Esophageal Cancer
}

\author{
Keita Takahashi $^{1} \cdot$ Katsunori Nishikawa $^{1} \cdot$ Kenei Furukawa $^{1} \cdot$ Yuichiro Tanishima $^{1}$. \\ Yoshitaka Ishikawa $^{1} \cdot$ Takanori Kurogochi $^{1} \cdot$ Masami Yuda $^{1} \cdot$ Yujiro Tanaka $^{1} \cdot$ Akira Matsumoto $^{1}$. \\ Norio Mitsumori ${ }^{1} \cdot$ Toru Ikegami $^{1}$
}

Published online: 11 August 2021

(c) Société Internationale de Chirurgie 2021

Correction to: World J Surg

https://doi.org/10.1007/s00268-021-06199-w

The last row of Table 3 was missing in the original online version of this article. The original article was corrected.

Publisher's Note Springer Nature remains neutral with regard to jurisdictional claims in published maps and institutional affiliations.

The original article can be found online at https://doi.org/10.1007/ s00268-021-06199-w.

Keita Takahashi

keita.takahashi@jikei.ac.jp

1 Department of Gastroenterological Surgery, Jikei University

School of Medicine, 3-25-8 Nishishimbashi, Minato-ku,

Tokyo 105-8461, Japan 